\title{
Modeling Risk Reduction in Agriculture Associated with Dangerous Agrometeorological Phenomena
}

\author{
B A Ashabokov1,2, L M Fedchenko³, A A Tashilova', A V Shapovalov, \\ A Kh Khavtsukov', and S B Balkarova ${ }^{4}$ \\ ${ }^{1}$ Department of Cloud Physics, Federal State Budgetary Institution, High-Mountain Geophysical \\ Institute, Nalchik, Russia \\ ${ }^{2}$ Institute of Informatics and Problems of Regional Management, KBSC of RAS, Nalchik, Russia \\ ${ }^{3}$ Chief researcher, Federal State Budgetary Institution, High-Mountain Geophysical Institute, \\ Nalchik, Russia \\ ${ }^{4}$ Institute of International Relations, Kabardino-Balkarian State University, Nalchik, Russia
}

Corresponding Author:

B A Ashabokov

ashabokov.boris@mail.ru

Received: 25 October 2019

Accepted: 15 November 2019

Published: 25 November 2019

Publishing services provided by Knowledge E

(c) B A Ashabokov et al. This article is distributed under the terms of the Creative Commons Attribution License, which permits unrestricted use and redistribution provided that the original author and source are credited.

Selection and Peer-review under the responsibility of the AgroSMART 2019 Conference Committee.

\section{Abstract}

The paper discusses possible approaches to reduce the risks associated with dangerous weather conditions. More specifically, the article considers the problem of reducing agricultural losses from such dangerous agrometeorological phenomena as hailstorm and drought. Within the framework of the decision-making theory, the formulation of the problem of reducing the losses of a considering industry from these phenomena is proposed -- the objective is making decisions under risk. The features of the information support of this problem and the main tasks arising in the way of its practical use are discussed. The results of calculations that are carried out to analyze the effectiveness of the proposed method are given. The results of the calculations showed that the method is quite effective and can be used to reduce agricultural losses from hail.

Keywords: hailsorms, agriculture, risk reduction, cause damage by hail, decisionmaking objective

\section{Introduction}

In recent decades, there has been a steady increase in the activity of natural hazards, which is a consequence of climate change. The number of such phenomena that can cause damage to the economy and the environment in the territory of the Russian Federation, for example, comes to 500 per year. A significant part of them (about $25 \%$ ) are local convective phenomena (rain, hail, squall, etc.) [4]; this quantity tends to increase. As an example, it can be noted that in 2016, in the whole territory of the Russian Federation, 988 hydrometeorological hazards were noted, 380 of which caused significant damage to sectors of the economy and vital activity of the population. 
It is obvious that the consequences of such trend in the dynamics of natural hazards can be extremely negative for the environment and for various spheres of human activity. In the future, the nature of the functioning of socio-economic systems at all levels will be determined by the magnitude of the losses from these phenomena [7]. This makes this study extremely relevant: tit addresses the problem of climate change and its consequences for various fields of activity and the environment, the development of scientifically based methods for reducing risks, including losses from dangerous weather events. It should be noted that studies carried out in these areas are quite intensive. For example, it may be noted in the works devoted to the study of the features of climate change on the territory of Kabardino-Balkarian Republic [1, 2, 5]. At the same time, the development of methods for reducing the risks associated with hazardous weather events faces serious difficulties.

In this paper, using the example of hailstorms, we consider possible approaches to reducing the risks associated with dangerous weather events, discuss some of the problems that arise on the way of implementing these approaches.

\section{Main Approaches to Reduce the Risks Associated with Hazardous Weather}

To reduce the risks associated with hazardous weather events, two approaches are possible. One of them (called active) is the intervention in those natural processes that are accompanied by dangerous weather phenomena. As an example, to reduce agricultural losses due to hail or lack of moisture in the soil, clouds are actively influenced to control the formation of precipitation in them (to prevent hail formation or increase precipitation). You can even say that this approach is the only one that is used to prevent hailstorms. Methods and technologies of active influence on clouds have been developing intensively since the second half of the last century, and practical work on the effects on convective clouds in order to prevent hail and control precipitation are carried out in many countries. But, despite all the advances in the physics of clouds and the active effects on them [3], a steady increase of losses from hailstorms will probably continue. This will be due to two main reasons: firstly, the effectiveness of methods for actively influencing clouds is still not sufficiently high, and secondly, due to climate warming, there is a steady increase in such characteristics of dangerous weather phenomena as frequency and power, and besides, there is an expansion of the territories seized by these phenomena [7]. The state of the physics of clouds and 
the active effects on them, as well as the directions of its development, are described in [3].

Another approach to risk reduction (called passive) does not imply interference in processes accompanied by dangerous weather phenomena. As an example, it can be noted that this approach can be considered the only one that is used to reduce the risks associated with slope processes.

The approach proposed below to reduce agricultural losses from these dangerous weather events does not imply an active influence on precipitation processes in the clouds. It is based on the fact that crops are the subject of varying degrees to the influence of dangerous weather phenomena, which makes the structure of crop production a mechanism for managing agricultural losses from these phenomena. Note that this approach to reducing agricultural losses due to hail and drought is not spread yet. This is due to the difficulties of developing the methods and models necessary for its practical use. These difficulties are mainly due to the lack of information, which is necessary for their development; it makes possible to consider this problem in the framework of the theory of decision-making $[6,8]$.

For example, in the case of hail processes, agricultural losses depend on many factors. These include characteristics of hail precipitation (hailstone size, hailstone distribution, their concentration, duration and area of hail precipitation, etc.) and production and economic indicators of agriculture at the time of hail precipitation, as well as hailstones characteristics. And, as it is known, the available information of hail processes is approximately limited and often has incomplete data of the radar characteristics of hail clouds, of the size distribution of hailstones on the ground, of the frequency and area of hail precipitation. In addition, the results of studies of the dependence of crop damage by hail on the phase of their development and the characteristics of hail precipitation are still significantly limited. Such features of the available information are a source of certain difficulties in solving such problems as the formation of a multitude of measures (actions) that can be used to reduce losses from hail and the selection of the most appropriate measure from this set.

\section{Statement of the Objective of Reducing the Risks in Agriculture Associated with Dangerous Agrometeoro- logical Phenomena}

Let us dwell on the formulation of the problem of reducing losses associated with dangerous weather phenomena. As was already noted, the features of information 
support make it natural to consider this problem in the framework of the theory of decision making. For specific weather hazards and specific sectors of the economy, including agriculture, this objective can be viewed as a single-criterion, decision-making objective, which greatly facilitates its solution. The formulation and solution of this problem for a specific hazardous weather phenomenon will be associated with the formation of a multitude of $A_{1}, A_{2}, A_{3}, \ldots, A_{M}$ events that can be used to reduce losses from this phenomenon, and the choice of the most appropriate measure using one or another criterion from this set, taking into account the peculiarities of occurrence of the considered weather phenomenon.

Let $U_{1}, U_{2}, U_{3}, \ldots, U_{N}$ be a denotation of the possible manifestations of dangerous weather phenomenon in a particular territory in the coming year (in the case of hailstorms, such options will be values of one of the indicators characterizing the activity of hail processes or hail hazard in a given area). Then each pair $\left(A_{i}, U_{j}\right)$ can be associated with some outcome $S_{i j}(i=1,2, \ldots, M ;, j=1,2, \ldots, N)$, which will be equal to the value of one of the indicators of production in agriculture. As an outcome, for example, the gross output of products, the magnitude of losses due to hail and the magnitude of the saved crop, etc. can be used. Select the most appropriate of the measures $A_{1}, A_{2}, A_{3}, \ldots, A_{M}$, then follow Table 1, which can be considered a decision-making model for reducing losses from dangerous weather events [8]:

TABLE 1: Outcomes $s_{i j}$, corresponding to measures $\mathrm{a}_{i}$ and conditions $\mathrm{u}_{j}$ of agriculture.

\begin{tabular}{|c|c|c|c|c|c|} 
& $\mathbf{U}_{1}$ & $\mathbf{U}_{2}$ & $\mathbf{U}_{3}$ & -- & $\mathbf{U}_{N}$ \\
\hline$A_{1}$ & $\mathrm{~S}_{11}$ & $\mathrm{~S}_{12}$ & $\mathrm{~S}_{13}$ & -- & $\mathrm{S}_{1 N}$ \\
\hline$A_{2}$ & $\mathrm{~S}_{21}$ & $\mathrm{~S}_{22}$ & $\mathrm{~S}_{23}$ & --- & $\mathrm{S}_{2 N}$ \\
\hline$A_{3}$ & $\mathrm{~S}_{31}$ & $\mathrm{~S}_{32}$ & $\mathrm{~S}_{33}$ & -- & $\mathrm{S}_{3 N}$ \\
\hline-- & --- & --- & -- & --- & -- \\
\hline $\mathbf{A}_{M}$ & $\mathrm{~S}_{M 1}$ & $\mathrm{~S}_{N 2}$ & $\mathrm{~S}_{M 3}$ & -- & $\mathrm{S}_{M N}$ \\
\hline
\end{tabular}

For a particular hazardous phenomenon --- hailstorms, let us consider two methods of forming the set $A_{1}, A_{2}, A_{3}, \ldots, A_{M}$, which is one of the most important objectives of the research problem. It should be borne in mind that the quality of the decision to reduce losses from natural hazards will largely depend on the successful formation of this set. The requirements that may be submitted to these activities should be taken into account. In the case of hailstorms, for example, the requirements for crop production should be taken into account, as well as the requirements for financial and other resources that should be used to produce them. 
In the case of marked agrometeorological hazards (hail, drought), there are two ways of forming this set. The first method is based on determining the elements of the set $A_{1}, A_{2}, A_{3}, \ldots, A_{M}$, by selecting the structures of agricultural crops, taking into account the restrictions imposed on the volumes of their production and on the volumes of resources used for this purpose. As disadvantages of this method, it can be noted that, firstly, the obtained set $A_{1}, A_{2}, A_{3}, \ldots, A_{M}$, can be quite limited, and its elements may be far from the most acceptable measure and, secondly, the formation of this set can be quite time consuming.

It should also be noted that the elements of the set $U_{1}, U_{2}, U_{3}, \ldots, U_{N}$ are the characteristics of hail processes that can be used to determine outcomes $S_{i j}(i=1,2, \ldots$, $M ;, j=1,2, \ldots, N)$. The presence of sets $A_{1}, A_{2}, A_{3}, \ldots, A_{M}$ and $U_{1}, U_{2}, U_{3}, \ldots, U_{N}$ allows you to determine the outcomes. Knowing them, the choice of the most appropriate of many activities can be done by using one of the known criteria [8].

To study the possibility of using this approach for making decisions to reduce risks in agriculture, some calculations were carried out. To find $\mathrm{U}_{1}, \mathrm{U}_{2}, \mathrm{U}_{3}, \ldots, \mathrm{U}_{N}$, data on the frequency of hail precipitation in a given area were analyzed over a period of 50 years, and as a result, this characteristic of hail processes was presented as a random variable (Table 2). It should be noted that the availability of such information about hazardous weather conditions makes it possible to consider the choice of the most appropriate measure in the form of a decision-making objective under risk conditions. Cases of hail fallout were considered as independent events.

TABLE 2: The number of days with hail $(n)$ and the probabilities pi $(i=1,2,3,4)$ corresponding to its different values, obtained according to the data of the period of 1958--2008.

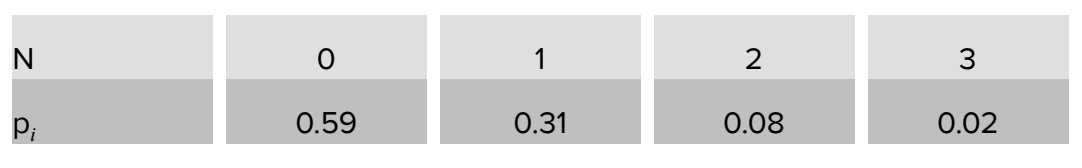

It can be noted from the table that the maximum number of hail processes in the climatic conditions of the area does not exceed 3 per year. In this case, the elements of the set $U_{1}, U_{2}, U_{3}, \ldots, U_{N}$ will be the probabilities $p_{1}, p_{2}, p_{3}, p_{4}$, corresponding to the possible values of $\mathrm{N}$. The areas of hail fallout were estimated based on long-term observations. In the calculations, the following values were used: $S_{1}=600$ ha, $S_{2}=$ 1000 ha, $S_{3}=700$ ha. The calculations were carried out for the main crops that are produced in the area: wheat, corn, oats, potatoes. In addition, data from the State Statistics Committee of Kabardino-Balkarian Republic were used on the production and economic indicators of agriculture in the area. As for the damage to crops by hail, the results of field studies for wheat and maize conducted at the High-Mountain Geophysical 
Institute $[9,10]$ were used. According to the results of these studies, with the same hail characteristics, the damage to wheat is noticeably higher than the damage to corn. In the case when the kinetic energy of hail is $100 \mathrm{~J} / \mathrm{m}^{2}$, for damageability of maize and wheat the following values were obtained: $\mathrm{kk}=0.37$ (or $37 \%$ ) and $\mathrm{kp}=0.7$ (or $70 \%$ ). For the rest of the cultures, due to the absence of such studies, the results of a survey of specialists were used. The damage of oats, according to these data, is less than the damage of wheat. It was suggested that the value of damage to oats corresponding to the marked value of hailstone is $60 \%$.

The calculations were carried out for the following production structures of the marked crops (the areas occupied by wheat, corn, oats and potatoes are shown in the $1^{\text {st }}, 2^{\text {nd }}$ and $3^{r d}$ areas):

1. $300,100,100,100$ ha, $500,200,200,100$ ha, $300,200,100,100$ ha.

2. $300,100,100,100$ ha, $500,200,200,100$ ha, $300,200,100,100$ ha.

3. $240,160,100,100$ ha, $400,300,200,100$ ha, $240,260,100,100$ ha.

4. $210,190,100,100$ ha, $350,350,200,100$ ha, $210,290,100,100$ ha.

5. $150,250,100,100$ ha, $250,450,200,100$ ha, $150,350,100,100$ ha.

6. $240,100,160,100$ ha, $400,200,300,100$ ha, $240,200,160,100$ ha.

7. $150,100,250,100$ ha, $250,200,450,100$ ha, $150,200,250,100$ ha.

8. $240,100,100,160$ ha, $400,200,200,200$ ha, $300,200,100,100$ ha.

9. $150,100,100,250$ ha, $250,200,200,350$ ha, $150,200,100,250$ ha.

10. $300,100,80,120$ ha, $500,200,160,140$ ha, $300,200,80,120$ ha.

You can see that many activities to reduce agricultural losses from hail consist of 10 elements. Gross production volumes (1 million rubles) in the absence of hail precipitation $(P O)$ and during hail precipitation $(P H)$ in the considered areas are given in Table 3. The values of these indicators in the $i$-th section were calculated using the expressions:

$$
\begin{gathered}
P 0_{i}=\sum_{j=1}^{4} x_{i j} Y_{i j} P r_{i j}, \\
P H_{i}=\sum_{j=1}^{4}\left(1-k_{i j}\right) x_{i j} Y_{i j} P_{i j},(i=1,2,3)
\end{gathered}
$$


TABLE 3: Gross volume of production in the considered areas in the absence of hail $\left(\mathrm{pO}_{1}, \mathrm{pO}_{2}, \mathrm{pO}_{3}\right)$ and the ceases of its occurrence $\left(\mathrm{ph}_{1}, \mathrm{ph}_{2}, \mathrm{ph}_{3}\right)$, expected values of the gross crop $(\mathrm{v})$, corresponding to the actions of 1-10 (1 million rubles).

\begin{tabular}{|c|c|c|c|c|c|c|c|}
\hline & $\mathbf{P O}_{1}$ & $\mathbf{P H}_{1}$ & $\mathbf{P O}_{2}$ & $\mathbf{P H}_{2}$ & $\mathbf{P O}_{3}$ & $\mathbf{P H}_{3}$ & $\mathbf{V}$ \\
\hline & $\mathbf{P}_{10}=\mathbf{0 . 5 9}$ & $\mathbf{P}_{1 h}=\mathbf{0 . 3 1}$ & $\mathbf{P}_{20}=\mathbf{0 . 9 2}$ & $\mathbf{P}_{2 h}=\mathbf{0 . 0 8}$ & $\mathbf{P}_{30}=\mathbf{0 . 9 8}$ & $\mathbf{P}_{3 h}=\mathbf{0 . 0 2}$ & \\
\hline $\mathbf{1}$ & 46.5 & 30.3 & 60.9 & 36.6 & 51.8 & 33.6 & 147.2 \\
\hline 3 & 47.1 & 31.0 & 61.8 & 37.7 & 52.4 & 34.3 & 149.4 \\
\hline 4 & 47.7 & 31.7 & 62.8 & 38.9 & 53.0 & 35.0 & 151.5 \\
\hline 5 & 48.2 & 32.4 & 63.7 & 40.1 & 53.5 & 35.7 & 153.4 \\
\hline 6 & 49.4 & 33.8 & 65.6 & 42.4 & 54.7 & 37.1 & 157.7 \\
\hline 7 & 45.8 & 30.2 & 59.7 & 36.5 & 51.1 & 33.6 & 145.0 \\
\hline 8 & 44.8 & 30.1 & 58.0 & 36.3 & 50.1 & 33.4 & 141.8 \\
\hline 9 & 84.7 & 43.5 & 86.2 & 58.5 & 67.0 & 46.8 & 200.5 \\
\hline 10 & 51.8 & 34.7 & 71.5 & 45.4 & 57.1 & 38.1 & 167.5 \\
\hline
\end{tabular}

where $x_{i 1}, x_{i 2}, x_{i 3}, x_{i 4}$-- are areas occupied by crops in the $i$-th area, $Y_{i 1}, Y_{i 2}, Y_{i 3}, Y_{i 4}$-are yields, $\operatorname{Pr}_{i 1}, \operatorname{Pr}_{i 2}, \operatorname{Pr}_{i 3 j}, \operatorname{Pr}_{i 4}$-- are sales prices and $k_{i 1}, k_{i 2}, k_{i 3}, k_{i 4}$-- are the damage by hail of these crops on the i-th site $(i=1,2,3)$.

It is noteworthy that gross production volumes at all sites in the absence of hail and during its occurrence depend substantially on the structure of the agricultural crops. In the case of measures 7 and 9, for example, the spread between the values of this indicator in the absence of hail in the second segment is 66.2 million rubles, which is noticeably greater than its minimum value. When hail occurs, there is a slight decrease in the spread between these indicators (up to 55.2 million rubles), which may be due to a decrease in gross output.

To select a more efficient structure of crop production, Laplace criterion was used [8]. According to this criterion, the best of the structures is the one that corresponds to the maximum of the expected gross output. In this regard, using the data of table 2 , it is necessary to determine the probabilities of absence $\left(p_{10}, p_{20}, p_{30}\right)$ and hail precipitation $\left(p_{1 h}, p_{2 h}, p_{3 h}\right)$ in sections 1, 2 and 3 . These probabilities are indicated in table 3 . Expected production volumes corresponding to different crop structures are calculated using the following expression:

$$
V=p_{10} \mathrm{PO}_{1}+p_{20} \mathrm{PO}_{2}+p_{30} \mathrm{PO}_{3}+p_{1 h} \mathrm{PH}_{1}+p_{2 h} \mathrm{PH}_{2}+p_{3 h} \mathrm{PH}_{3}
$$




\section{Conclusion}

The approach to reducing agricultural losses from such dangerous agrometeorological phenomena as hail is proposed. As a mechanism to reduce losses in the approach, the difference in damage to crops by hail is used. Accordingly, the management of agricultural losses from this dangerous weather phenomenon is carried out by varying the structure of crop production. In the framework of the decision-making theory, the agriculture loss reduction model was formulated using this approach, which was reduced to solving the optimization problem (a linear programming problem). The results of the model calculations showed a high efficiency of the approach for reducing agricultural losses from hailstorms.

\section{References}

[1] Archestov, G.Kh. (2014). Analysis and forecast of changes in precipitation regime in the foothill part of the territory of the Kabardino-Balkarian Republic. News of the Kabardino-Balkarian Scientific Center of the Russian Academy of Sciences, vol. 4, no. 4 , pp. 5--11.

[2] Archestov, G.Kh., Balkizova, A.Kh., Orsaeva, I.M. (2014). On a approach and some results of forecasting the dynamics of agro-climatic resources. News of the Kabardino-Balkarian Scientific Center of the Russian Academy of Sciences, vol. 1, no. 56, pp. 17--23.

[3] Ashabokov, B.A., Fedchenko, L.M., Shapovalov, A.V., Shapovalov, V.A. (2017). Physics of clouds and active influences on them. Nalchik: Printing House, $240 \mathrm{p}$.

[4] Ashabokov, B.A., Tashilova, A.A., Kesheva, L.A., Teunova, N.V. (2017). Report on climate features in the territory of the Russian Federation for 2016. Sections Temperature, Precipitation, pp. 16--17, 21--22, Retrieved from: http://climatechange. igce.ru/index.php?option=com_docman\&ltemid=73\&gid=27\&lang=ru

[5] Balkizova, A.Kh., Tashilova, A.A., Pshikhacheva, I.N. (2013). The main stages and tasks of the adaptation of the agricultural sector to climate change", Materials of the International Symposium Sustainable Development: Problems, Concepts, Models, vol. 1, pp. 106--109. Kabardino-Balkarian Scientific Center of the Russian Academy of Sciences.

[6] Kini, R.L., Rife, Kh. (1981). Decision-making under many criteria: preferences and substitutions. Moscow: Radio and communication, $560 \mathrm{p}$. 
[7] Bolin, B., Dees, B., Yager, J., Warwick, R. (1989). Greenhouse effect, climate change and ecosystems. Leningrad: Hydrometeoizdat, 558 p.

[8] Takha, Kh. (1985). Introduction to Operations Research, vol. 2. Moscow: Mir, 496 p.

[9] Tlisov, M.I., Taumurzaev, A.Kh., Fedchenko, L.M., Khuchunaev, B.M. (1987). Physical characteristics of hail and damage to crops. Proceedings of VGI, iss. 74, pp. 137--144.

[10] Tlisov, M.I., Taumurzaev, A.Kh., Fedchenko, L.M., Khuchunaev, B.M. (1991). Kinetic characteristics of hail and damage to crops. Proceedings of the All-Union Seminar Active effects on hail processes and improvement of ice-forming reagents for the practice of active effects, pp. 75--77. 